\title{
Correlations between magnetism, microstructure, crystallography, and phase stability in $\mathrm{GdNi}_{1-\mathrm{x}} \mathrm{Co}_{\mathrm{x}}$ alloys
}

\author{
Y. Mudryk, ${ }^{1, \mathrm{a}}$ D. Paudyal, ${ }^{1}$ T. Prost, ${ }^{1,2}$ S. Chumbley, ${ }^{1,2}$ V. K. Pecharsky, ${ }^{1,2}$ and
}

\author{
K. A. Gschneidner, Jr. ${ }^{1,2}$ \\ ${ }^{1}$ Ames Laboratory of the USDOE, Iowa State University, Ames, Iowa 50011-3020, USA \\ ${ }^{2}$ Department of Materials Science and Engineering, Iowa State University, Ames, Iowa
} 50011-2030, USA

Relationships between the electronic structure, magnetostriction, and phase stability of the $\mathrm{GdNi}_{1-\mathrm{x}} \mathrm{Co}_{\mathrm{x}}$ system have been investigated. Increasing the concentration of Co in $\mathrm{GdNi}_{1-\mathrm{x}} \mathrm{Co}_{\mathrm{x}}(0 \leq \mathrm{x}<0.5)$ series leads to anisotropic changes of lattice parameters within the CrB-type crystal structure which are qualitatively similar to, but are stronger than, those observed upon the application of magnetic field to the Co-free, binary GdNi near its Curie temperature, $\mathrm{T}_{\mathrm{C}}$. The magnetic field and temperature dependent $\mathrm{X}$-ray powder diffraction study of $\mathrm{GdNi}_{0.85} \mathrm{Co}_{0.15}$ shows that the strong linear thermal expansion effects near $\mathrm{T}_{\mathrm{C}}$ are, however, absent. Density functional theory calculations show that GdCo has positive formation energy, and density of states at the Fermi level indicates intrinsic instability of $\mathrm{GdCo}$ as opposed to GdNi. The enhanced exchange interaction energy of GdCo compared to GdNi supports the experimentally observed increasing Curie temperature of $\mathrm{GdNi}_{1-\mathrm{x}} \mathrm{Co}_{\mathrm{x}}$ with increasing $x(\mathrm{Co})$.

\footnotetext{
${ }^{\text {a } C o r r e s p o n d i n g ~ a u t h o r: ~ s l a v k o m k @ a m e s l a b . g o v ~}$
} 


\section{Introduction}

Magnetostriction observed as changes of dimensions of a solid in response to an applied external magnetic field is an interesting subject for research due to both its practical significance and the underlying physics. The quick (less than a millisecond) and often anisotropic response of alloy's dimensions to a varying magnetic field strength can be fine-tuned and precisely calibrated in materials such as Terfenol-D $\left(\mathrm{Tb}_{0.3} \mathrm{Dy}_{0.7} \mathrm{Fe}_{2}\right)$ and Galfenol (Fe-Ga), which find applications in sound and vibration sources, sonar systems, mechanical impact actuators, active vibration control (shock absorbers), micro-motional control, materials processing, and electromechanical converters. ${ }^{1}$ The effect may originate at the electronic (varying exchange interactions), atomic (change of interatomic distances and lattice parameters), and nano- to micro- (varying orientations of domains and/or twins) scales, or it may simultaneously occur at all scales. The magnetostriction is often anisotropic, which at the atomic level may lead to lattice deformations, including changes of lattice symmetry. ${ }^{2}$

The spontaneous anisotropic magnetostriction in GdNi was originally reported by Gratz et al., ${ }^{3}$ and physical behaviors of this compound have been studied extensively using both experimental and theoretical methods. ${ }^{4-16}$ The unusual magnetostriction of this compound was recently explained using first-principles calculations complemented by thorough experimental measurements performed on the GdNi alloy prepared from high-purity components. ${ }^{17}$ Charge transfer from the Gd $5 d$ to the Ni $3 d$ bands near the magnetic ordering temperature $\left(\mathrm{T}_{\mathrm{C}}\right)$ leads to the change in the $\mathrm{Ni}-\mathrm{Ni}, \mathrm{Gd}-\mathrm{Ni}$, and $\mathrm{Gd}-\mathrm{Gd}$ 
interatomic distances. In turn, these changes result in lattice expansion along the $a$ - and $b$ crystallographic directions and contraction along the $c$-axis.

It is also well known that the crystal structure of the GdNi compound, which is of $\mathrm{CrB}$ type, can be easily altered through chemical substitutions. For example, in the $\mathrm{GdNi}_{1-\mathrm{x}} \mathrm{Cu}_{\mathrm{x}}$ system, increasing $x$ first leads to the formation of the closely related FeBtype structure, ${ }^{9,12,18}$ which is then converted to the $\mathrm{CsCl}$-type structure that $\mathrm{GdCu}$ adopts at room temperature (a martensitic transformation from the CsCl-type into the FeB-type structure occurs at low temperatures). ${ }^{19}$ Even more interesting are substitutions of the rare earth element, $\mathrm{Gd}$, by other rare earth elements, which result in a variety of quite complex intermetallic structures. ${ }^{20}$

Further, Gd does not form equiatomic compounds with transition elements with $3 d$ shells less occupied than those of $\mathrm{Ni}$, i.e. with $\mathrm{Co}, \mathrm{Fe}$, or $\mathrm{Mn}$. Reports on properties of amorphous GdCo thin films or composites exist in the literature ${ }^{21}$ but no thermodynamically stable GdCo compound has been reported. There is little difference between the effective atomic sizes of $\mathrm{Ni}$ and $\mathrm{Co}$, hence the electronic structure must be the main factor determining the stability of equiatomic binary GdNi and GdCo compounds. Further, since changes of the electronic structure control the magnetostriction of $\mathrm{GdNi}^{17}$ the substitution of $\mathrm{Co}$ for $\mathrm{Ni}$ is expected to affect magnetostrictive behavior of $\mathrm{GdNi}_{1-\mathrm{x}} \mathrm{Co}_{\mathrm{x}}$ alloys as well. In this paper we show how electronic structure and magnetostriction are interrelated in this system. Coupled experimental (magnetic, crystallographic, and microstructural) and theoretical (first principles) studies show how the substitution of Ni by Co decreases the stability of the 
CrB-type crystal structure and affects anisotropic changes of lattice parameters near the magnetic ordering temperature.

\section{Experimental Methods}

The $\mathrm{GdNi}_{1-\mathrm{x}} \mathrm{Co}_{\mathrm{x}}$ alloys were prepared by arc melting of the pure metals under argon atmosphere. Gadolinium was obtained from the Materials Preparation Center of the Ames Laboratory, ${ }^{22}$ (purity 99.86 at.\% with respect to all elements), and $\mathrm{Ni}$ and Co were purchased from commercial vendors (purity $>99.9$ at.\%). The $\mathrm{GdNi}_{0.85} \mathrm{Co}_{0.15}$ alloy was prepared as a $10 \mathrm{~g}$ button while other compositions were $\sim 5 \mathrm{~g}$ buttons. The alloys were re-melted six times to ensure homogeneity. The weight losses during arc-melting were nearly negligible, i.e. they were on the order of $0.1 \mathrm{wt} . \%$. The samples were initially heat treated at $800{ }^{\circ} \mathrm{C}$ for 7 days. However, the samples with $\mathrm{x}=0.5$ and 1.0 melted at this temperature, indicating the presence of a deep eutectic in the $\mathrm{GdNi}_{1-\mathrm{x}} \mathrm{Co}_{\mathrm{x}}$ pseudobinary system in the Co rich region. All compositions were then heat treated at $700^{\circ} \mathrm{C}$ for 18 days but the samples of $\mathrm{x}=0.5$ and 1.0 compositions also melted after the annealing at $700{ }^{\circ} \mathrm{C}$. The heat-treatment at 700 or $800{ }^{\circ} \mathrm{C}$ temperatures neither substantially affects the crystal structure of the majority phase nor the magnetic ordering temperatures of Ni-rich $\mathrm{GdNi}_{1-\mathrm{x}} \mathrm{Co}_{\mathrm{x}}$ samples.

The X-ray powder diffraction patterns at room temperature were collected using PANalytical X'Pert powder diffractometer ( $\mathrm{Cu} \mathrm{K}_{1}$ radiation). Samples for SEM analysis were mechanically polished, while TEM samples were twin-jet thinned in an electrolyte of methanol and perchloric acid. Electron microscopy imaging and characterization was 
performed on both a JEOL 5910 SEM with a Noran Vantage EDS system, and an FEI Tecnai $\mathrm{G}^{2}$ F20 TEM.

Magnetic properties were measured using a Quantum Design MPMS XL-7

magnetometer. The temperature and magnetic field dependent X-ray powder diffraction measurements of $\mathrm{GdNi}_{0.85} \mathrm{Co}_{0.15}$ sample were carried out as a function of temperature between 5 and $300 \mathrm{~K}$ in constant magnetic fields of 0 and $40 \mathrm{kOe}$, and as a function of magnetic field at $120 \mathrm{~K}$ on a Rigaku TTRAX rotating anode powder diffractometer employing Mo $\mathrm{K}_{\alpha}$ radiation. The diffractometer was equipped with a continuous flow ${ }^{4} \mathrm{He}$ cryostat controlling the temperature of a sample with $\pm 0.05 \mathrm{~K}$ accuracy, and a split-coil superconducting magnet creating a homogeneous DC magnetic field around the specimen. $^{23}$

\section{Experimental results}

The $\mathrm{GdNi}_{1-\mathrm{x}} \mathrm{Co}_{\mathrm{x}}$ series of alloys was prepared with $x$ (nominal) $=0,0.05,0.1,0.15,0.2$, $0.3,0.5$, and 1.0. The X-ray powder diffraction patterns of as cast alloys (except $x=1.0$ ) collected at ambient conditions are shown in Figure 1(c). The CrB-type structure is observed up to $x=0.3$, as confirmed by the Rietveld refinement of all collected X-ray patterns (the refined patterns are shown for $x=0$ and $x=0.3$ in Figures 1(a) and 1(b), respectively). Strong anisotropic shifts in Bragg peak positions indicating anisotropic changes of lattice parameters as well as a significant Bragg peak broadening gradually develop for high $x$. For $x=0.5$ the appearance of new Bragg peaks in addition to those of the CrB-type structure indicates the multi-phase nature of the $\mathrm{GdNi}_{0.5} \mathrm{Co}_{0.5}$ alloy, and the 
termination of the $\mathrm{GdNi}_{1-\mathrm{x}} \mathrm{Co}_{\mathrm{x}}$ solid solution when $x>0.3$. The examination of the $\mathrm{X}$-ray pattern of the sample with $x=1.0$ confirms that the GdCo compound does not exist, in agreement with literature. ${ }^{24}$ In fact, only $\mathrm{GdCo}_{2}$ and $\mathrm{Gd}_{4} \mathrm{Co}_{3}$ phases were detected by Xray powder diffraction analysis of the as cast GdCo sample.

A scanning electron microscopy investigation of the annealed, near-end member of the $\mathrm{GdNi}_{1-\mathrm{x}} \mathrm{Co}_{\mathrm{x}}$ solid solution, i.e. $x=0.3$, shows that this alloy indeed contains 95 vol. $\%$ of the main phase and confirms that the solid solution extends at least up to $x(\mathrm{Co})=0.3$. The existence of small inclusions $(\leq 10 \mu \mathrm{m}$ diameter $)$ of a secondary phase was observed. Energy dispersive X-ray spectroscopy (EDS) analyses of the observed spots reveal they have a composition of $\mathrm{Gd}(\mathrm{Ni}, \mathrm{Co})_{2}$, while the matrix remains near the nominal composition (Figure 2). Qualitative EDS measurements were complimented with more quantitative wavelength-dispersive X-ray spectroscopy (WDS) analysis of several samples, which confirms that the actual chemical composition of the matrix phase is nearly identical to the nominal and, therefore, can be accepted as such (Table 1). Thus, the Bragg peak broadening observed in the X-ray powder diffraction patterns (Fig. 1) does not appear to originate from the multiphase nature of the sample.

GdNi forms congruently from the melt and forms a eutectic at (Gd-56.5at\% Ni) with $\mathrm{GdNi}_{2}$ at $880{ }^{\circ} \mathrm{C}$. Yet, the presence of the $\mathrm{Gd}(\mathrm{Ni}, \mathrm{Co})_{2}$-based phase can be expected due to the absence of the equiatomic GdCo phase in the Gd-Co phase diagram. ${ }^{25}$ Magnetization measurements are in agreement with this observation as a weak anomaly corresponding to the magnetic ordering of the $\mathrm{Gd}(\mathrm{Ni}, \mathrm{Co})_{2}$ phase was observed in lowfield measurements. 
The lattice parameters of the $\mathrm{GdNi}_{1-\mathrm{x}} \mathrm{Co}_{\mathrm{x}}$ alloys were determined from the Rietveld refinements of the obtained room temperature X-ray powder diffraction patterns illustrated in Figure 1(c), and the results are shown in Figure 3(a). For comparison, the magnetic field dependence of the lattice parameters of the parent GdNi alloy measured at $60 \mathrm{~K}$ is shown in Fig. 3(b). It is easy to see that in both cases the lattice parameters change in a similar fashion although the chemical substitution obviously has a much stronger effect on the lattice. The lattice parameters dependence is nearly linear up to $x=$ 0.3 , suggesting that the $\mathrm{GdNi}_{1-\mathrm{x}} \mathrm{Co}_{\mathrm{x}}$ solid solution exists at least until $x(\mathrm{Co})=0.3$.

The magnetic measurements of heat-treated samples generally support X-ray diffraction and microscopy data, but they also show some differences. As illustrated in Fig. 4, the compositional dependence of the magnetic ordering temperature is not typical for a continuous solid solution, and while there is a steady linear increase in $T_{\mathrm{C}}$ between $x=0$ and $x=0.15$, further replacement of $\mathrm{Ni}$ by Co results in a much weaker increase of the magnetic ordering temperature $\left(\mathrm{T}_{\mathrm{C}}\right)$ for $x=0.2$, followed by a minor decrease of $\mathrm{T}_{\mathrm{C}}$ for $x$ $=0.3$. In addition to the main ordering transitions, weak high-temperature anomalies have been observed in the paramagnetic region (not shown in Figure 4); these may be attributed to minor quantities of the $\mathrm{Gd}(\mathrm{Ni}, \mathrm{Co})_{2}$ impurity phases, which are not observed in the X-ray data but were identified by SEM/EDS (see above). As expected, the temperatures of these anomalies increase with $x(\mathrm{Co})$. The $\mathrm{M}(\mathrm{T})$ anomalies attributed to $\mathrm{Gd}\left(\mathrm{Ni}_{1-\mathrm{x}} \mathrm{Co}_{\mathrm{x}}\right)_{2}$ impurities exist in all ternary samples except $\mathrm{GdNi}_{0.95} \mathrm{Co}_{0.05}$. As follows from Fig. 4(b), one may infer that based on the magnetic measurements the continuous solid solution does not exist in this system when $x(\mathrm{Co})$ exceeds 0.2 . Such discrepancy 
between magnetic and $\mathrm{XRD} /$ microscopic results is unusual, and warrants a more detailed investigation of the microstructure of Co-rich alloys.

TEM data of $\mathrm{GdNi}_{0.7} \mathrm{Co}_{0.3}$ (Fig. 5) show a much more complicated microstructure than observed by SEM. Due to a different length scale of TEM images compared to SEM, the $\mathrm{Gd}(\mathrm{Ni}, \mathrm{Co})_{2}$ impurity is no longer observed. However, linear features (marked by black arrows) of an unknown nature are clearly visible in the microstructure. While a separate study, which goes beyond the scope of this work, is needed in order to conclusively determine the nature of these linear features, several possibilities can still be suggested. First, these linear features may reflect stacking faults, twin boundaries, local ordering of $\mathrm{Ni} / \mathrm{Co}$ atoms, or even a planar impurity phase as has been reported in $\mathrm{R}_{5} \mathrm{~T}_{4}(\mathrm{R}=$ rare earth, $\mathrm{T}=\mathrm{Si}, \mathrm{Ge}$ ) compounds. ${ }^{26,27,28}$ In the latter, the volume faction of the second phase has always been below the limits of detection by X-ray powder diffraction. Hence, it is possible that the linear features present in $\mathrm{GdNi}_{0.7} \mathrm{Co}_{0.3}$ belong to a third phase in addition to $\mathrm{Gd}(\mathrm{Co}, \mathrm{Ni})_{2}$ observed in SEM. The extremely low concentration of such a planar impurity phase, however, suggests that it would have no measurable effect on the magnetic properties as was the case with the planar phases seen in $\mathrm{R}_{5} \mathrm{~T}_{4}{ }^{29}$

Second, bright field images (Fig. 5) reveal diffraction contrast in the form of pairs of dark lines (marked by white arrows, and referred to as bend contours). Bend contours pass through the linear features exhibiting minor but clear distortions, likely indicating lattice stress. Hence, the linear features themselves can produce stressed regions and structural imperfections; we note that such explanation is commensurate with a significant line broadening observed in the $\mathrm{X}$-ray powder diffraction patterns of $\mathrm{GdNi}_{1-\mathrm{x}} \mathrm{Co}_{\mathrm{x}}$ alloys as 
$x(\mathrm{Co})$ increases (Fig. 1). Higher stress levels here are likely associated with local atomic disorder due to a random distribution of $\mathrm{Co}$ and $\mathrm{Ni}$ atoms within a single available lattice site as indicated by broader Bragg reflections. They increasingly develop with increasing $x(\mathrm{Co})$ and may indeed lead to reduced exchange interactions and lower $\mathrm{T}_{\mathrm{C}}$ 's towards the end of the solid solution compared to a much more ideal crystallographic order that exists at the beginning of the same, i.e. at low $x(\mathrm{Co})$.

Figure 6 summarizes the magnetic properties of $\mathrm{GdNi}_{0.85} \mathrm{Co}_{0.15}$ (annealed at $800{ }^{\circ} \mathrm{C}$ for 7 days). The high-field (30 kOe) data show a linear dependence of the inverse magnetic susceptibility vs. temperature above $\mathrm{T}_{\mathrm{C}}$. The effective magnetic moment is $7.9 \mu_{\mathrm{B}} /$ f.u., close to the theoretical value of $7.94 \mu_{\mathrm{B}}$ for a free $\mathrm{Gd}^{3+}$ ion. The net magnetic moment in the ferromagnetic state is $7.14 \mu_{\mathrm{B}} /$ f.u. at $\mathrm{T}=2 \mathrm{~K}$ which compares well to that of $\mathrm{GdNi}$ $\left(7.1 \mu_{\mathrm{B}} /\right.$ f.u. $\left.{ }^{17}\right)$. Experimental data, therefore, indicate that both $\mathrm{Co}$ and $\mathrm{Ni}$ are practically non-magnetic in $\mathrm{GdNi}_{0.85} \mathrm{Co}_{0.15}$; this conclusion is in line with earlier first-principles calculations of $\mathrm{GdNi}$, where the calculated $3 d$ moments of $\mathrm{Ni}$ were on the order of -0.1 $\mu_{\mathrm{B}} /$ f.u. ${ }^{17}$.

Despite a negligible contribution from $3 d$ moments, replacing Ni by Co has a strong effect on the electronic density of states (see the results of the electronic structure calculations below). Therefore, even a moderate Co substitution has a strong influence on the physical and, especially, crystallographic behavior of the parent GdNi compound. In a binary $\mathrm{GdNi}$, magnetic ordering drives the room temperature $\mathrm{CrB}$-type lattice from a local energy minimum which the system occupies in the paramagnetic state, into a ground state energy minimum typical for a ferromagnetically ordered GdNi (see Fig. 5 of 
Ref. 17). The result is a highly anisotropic spontaneous striction which is, however, not the case in $\mathrm{GdNi}_{0.85} \mathrm{Co}_{0.15}$ as illustrated in Fig. 7. Weak anomalies are observed at $T_{\mathrm{C}}$ but, for the most part, the temperature dependencies of lattice parameters in a zero magnetic field and, especially, in a $40 \mathrm{kOe}$ magnetic field follow conventional thermal expansion behavior. From Figure 7, the most pronounced lattice parameter anomaly occurs along the $c$-axis but it has to be noted that the absolute size of this anomaly is quite small (on the order of $0.002 \AA$ ). In fact, based on the values of least squares standard deviations for the lattice parameters presented in Figure 7, one may suggest that such anomaly is almost statistically insignificant.

From the analysis of lattice parameters (also see Fig. 3) we conclude that $\mathrm{GdNi}_{0.85} \mathrm{Co}_{0.15}$ is already in the global energy minimum both below and above $T_{\mathrm{C}}$ due to Co substitution. Further, Fig. 3 illustrates that chemical and magnetic effects are strongly coupled in these Gd-based system; Co substitutions play a role of a chemical analogue of the temperature and magnetic field induced striction observed in GdNi with chemical effects being more than an order of magnitude stronger when compared with the effect imparted on the lattice by temperature (i.e. due to a spontaneous magnetic ordering) or external magnetic field of $40 \mathrm{kOe}$. One may argue, however, that in much larger applied magnetic fields the magnetostriction of $\mathrm{GdNi}$, which as follows from Fig. 3b shows no sign of saturation, may substantially increase, potentially becoming comparable with the lattice parameter changes caused by the Co substitution.

We note that anisotropic changes of the unit cell in $\mathrm{GdNi}$ and $\mathrm{GdNi}_{1-x} \mathrm{Co}_{x}$ are related to the changes in the electronic structure and to the transition between the local PM and the 
global FM energy minima, which occur at different $c / a$ and $b / a$ ratios and can be induced either by physical or chemical factors. ${ }^{17}$ The difference between these two minima is rooted in the strong $5 \mathrm{~d}-3 \mathrm{~d}$ hybridization observed in the FM state, ${ }^{17}$ which can be affected by magnetic ordering, by external magnetic field, or by replacement of weakly magnetic Ni with magnetically more active Co.

\section{Theoretical investigation}

The local spin density approximation including Hubbard $U$ - onsite electron-correlation $(\mathrm{LSDA}+U)^{30}$ approach has been employed to investigate the electronic structure and magnetic properties of hypothetical "GdCo" and real GdNi compounds. Calculations have been performed using the scalar relativistic version (which includes the mass velocity and Darwin correction terms) of the $\mathrm{LSDA}+U$ method implemented in the tight binding linear muffin tin orbital (TB-LMTO) ${ }^{31}$ and full potential linear augmented plane wave (FP-LAPW) ${ }^{32}$ methods. We used $U=6.7 \mathrm{eV}$ and $J=0.7 \mathrm{eV}-$ the well-known values for Gd atoms. The $\mathrm{k}$-space integrations have been performed with $16 \times 16 \times 16$ Brillouin zone mesh which was sufficient for the convergence of the total energies accurate to $\sim 0.05 \mathrm{meV} / \mathrm{f}$.u. and magnetic moments accurate to $\sim 0.01 \mu \mathrm{B} /$ atom. The experimentally determined lattice parameters and coordinates of atoms in the CrB-type crystal structure, which contains 8 atoms per unit cell, were used in these calculations.

To analyze the difference in thermodynamic stability between hypothetical "GdCo" that does not exist and GdNi (which exists), we have calculated and compared the density of 
states (DOS) of "GdCo" and GdNi. Figure 8a shows DOS of "GdCo" calculated using the CrB-type crystal structure and lattice constants of GdNi measured at $20 \mathrm{~K}^{17}$ Without spin polarization (paramagnetic, PM, state), the steep occupied DOS contributed by Co $3 \mathrm{~d}$ is located just below the Fermi level indicating a likely structural instability. The PM DOS peak splits into spin up and spin down states when magnetic ordering is imposed in the system; as expected, exchange splitting indicates ferrimagnetic coupling between Gd and Co moments.

Figure $8 \mathrm{~b}$ shows total DOS of GdNi calculated using its structural parameters obtained at $20 \mathrm{~K}$, i.e. the same as for "GdCo" above. The PM DOS contributed by Ni $3 \mathrm{~d}$ is located far below the Fermi level indicating a stable CrB-type crystal structure. In GdNi, compared to "GdCo" (Fig. 8a), exchange splitting upon spin polarization is much weaker indicating a nearly negligible Ni moment antiparallel with Gd moment. Further, a broad peak just below the Fermi level (at $\sim-0.2 \mathrm{eV}$ ) contributed by Gd $5 \mathrm{~d}$ in the PM DOS also splits into two peaks separated by $\sim 0.6 \mathrm{eV}$ around the Fermi level. As pointed out earlier, ${ }^{17}$ when the band splitting due to magnetic ordering increases, the system simultaneously rearranges its structure by changing the lattice parameters and interatomic distances to lower the total energy of the FM state. This illustrates that the second-order transformation between PM GdNi and FM GdNi is driven by the magnetism through spin splitting of Gd 5d states.

Considering a large effect of Co on the unit cell dimensions of GdNi (Fig. 3b), DOS of "GdCo" depicted in Fig. 8c was calculated using the same CrB-type crystal structure but 
with the lattice constants of $\mathrm{GdNi}_{0.7} \mathrm{Co}_{0.3}$ measured at room temperature. The DOS is slightly broadened compared to Fig. 8a but the main features remain similar. Hence, substantial changes in the lattice parameters of $\mathrm{GdNi}_{1-\mathrm{x}} \mathrm{Co}_{\mathrm{x}}$ as a result of chemical substitution do not cause significant changes in DOS of "GdCo". Lattice parameters have minor effect on DOS of GdNi because when computed using room temperature lattice constants of $\mathrm{GdNi}_{0.7} \mathrm{Co}_{0.3}$ (Fig. 8d) DOS no longer shows a clear Gd 5d splitting at the Fermi level, remaining very close to PM GdNi where there is no exchange splitting of Gd $5 \mathrm{~d}$.

The formation energies of "GdCo" and $\mathrm{GdNi}$, calculated by subtracting the total energy of components from the total energy of the alloy, are $170 \mathrm{meV} / \mathrm{f} . \mathrm{u}$. and $-350 \mathrm{meV} / \mathrm{f} . \mathrm{u}$. ., respectively (the formation energy calculations from density functional theory are at 0 K). In agreement with experiment, the negative formation energy confirms the stability of GdNi whereas the positive formation energy indicates GdCo to be unstable. The calculated effective magnetic exchange interactions for the hypothetical "GdCo" are higher ( $37 \mathrm{meV} /$ f.u.) compared to $\mathrm{GdNi}(20 \mathrm{meV} / \mathrm{f}$. u.). This predicts that effective exchange interactions may be enhanced while substituting Ni sites by Co, thereby increasing the Curie temperatures of $\mathrm{GdNi}_{1-x} \mathrm{Co}_{x}$ with increasing $x(\mathrm{Co})$, which is in a good agreement with experiment. 


\section{Conclusions}

Investigation of the $\mathrm{GdNi}_{1-\mathrm{x}} \mathrm{Co}_{\mathrm{x}}$ quasibinary system showed that the magnetostriction effect caused by the spontaneous magnetic ordering or by the application of magnetic field in binary GdNi is qualitatively similar to the chemically induced modification of lattice parameters of $\mathrm{GdNi}_{1-\mathrm{x}} \mathrm{Co}_{\mathrm{x}}$ alloys as a result of $\mathrm{Ni} / \mathrm{Co}$ substitution. These effects are related to the electronically driven changes of the positions of the energy minima described earlier for $\mathrm{GdNi}^{17}$ where the PM state is stable within specific $c / a$ and $b / a$ boundaries and the FM state is stable inside a region delineated by different values of $c / a$ and $b / a$. At the same time, the magnetic field and temperature dependent X-ray powder diffraction study revealed that the strong linear thermal expansion effects observed in GdNi near $\mathrm{T}_{\mathrm{C}}$ nearly disappear in the $\mathrm{GdNi}_{0.85} \mathrm{Co}_{0.15}$ alloy due to modification of the electronic structure that have already occurred with $\mathrm{Ni} / \mathrm{Co}$ substitution. The $\mathrm{GdNi}_{1-\mathrm{x}} \mathrm{Co}_{\mathrm{x}}$ solid solution terminates near $\mathrm{x} \sim 0.3$ and unusual linear microstructural features were observed in the $\mathrm{GdNi}_{0.7} \mathrm{Co}_{0.3}$ alloy. Their presence may be related to the lattice stress, which, according to the X-ray powder diffraction data progressively increases with the increase of $x(\mathrm{Co})$ or they may belong to an unknown minor phase. The local spin density approximation with the onsite electron-correlation - Hubbard U parameter - (LSDA+U) calculations confirm the formation of $\mathrm{GdNi}$ with the $\mathrm{CrB}$-type orthorhombic structure but not GdCo. The positive formation energy and unstable density of states close to the Fermi level are the main causes for the instability of GdCo. 


\section{Acknowledgements}

The Ames Laboratory is operated for the U. S. Department of Energy by Iowa State University of Science and Technology. This work was supported by the Department of Energy, Office of Basic Energy Sciences, Materials Sciences Division under contract No. DE-AC02-07CH11358.

\section{References}

${ }^{1}$ G. Engdahl and C.B Bright, in Handbook of Giant Magnetostrictive Materials, edited by G. Engdahl (Academic Press, San Diego, 2000), Chap. 5, p.287.

2 A. Lindbaum and M. Rotter, in Handbook of Magnetic Materials, edited by K. H. J. Buschow (Elsevier, 2002), Vol. 14, Chap. 4, p.307.

3 E. Gratz and A. Lindbaum, J. Magn. Magn. Mater. 177, 1077 (1998).

${ }^{4}$ K. Uhlířová, J. Prokleška, J. Poltierová Vejpravová, V. Sechovský, and K. Maezawa, J. Magn. Magn. Mater. 310, 1753 (2007).

5 R.E. Walline and W.E. Wallace, J. Chem. Phys. 41, 1587 (1964).

6 S.C. Abrahams, J.L. Bernstein, R.C. Sherwood, J.H. Wernick, and H.J. Williams, J. Phys. Chem. Solids 25, 1069 (1964).

${ }^{7}$ K. Sato, Y. Isikawa, K. Mori, and T. Miyazaki, J. Appl. Phys. 67, 5300 (1990).

${ }^{8}$ C. B. Zimm, W.F. Stewart, J.A. Barclay, C.K. Campenni, W. Overton, C. Olsen, D. Harding, R. Chesebrough, and W. Johanson, Adv. Cryogenic Eng. 33, 791 (1988). 
9 J.A. Blanco, M. Castro, R. Burriel, D. Gignoux, and D. Schmitt, Solid State Commun. 89, 389 (1994).

${ }^{10}$ V.L.B. de Jesus, V.M.T.S. Barthem, I.S. Oliveira, and A.P. Guimarães, J. Magn. Magn. Mater. 177, 1125 (1998).

${ }^{11}$ R. Mallik, P.L. Paulose, E.V. Sampathkumaran, S. Patil, and V. Nagarajan, Phys. Rev. B 55, 8369 (1997).

12 J. A. Blanco, J.C. Gomez Sal, J. Rodriguez Fernandez, D. Gignoux, D. Schmitt, and J. Rodriguez-Carvajal, J. Phys.: Condens. Matter 4, 8233 (1992).

${ }^{13}$ K. Yano, I. Umehara, K. Sato, and A. Yaresko, Solid State Commun. 136, 67 (2005).

${ }^{14}$ J. Rusz, I. Turek, and M. Divis, Phys. Rev. B 71, 174408 (2005).

${ }^{15}$ P. de la Presa and M. Forker, Hyperfine Interactions 158, 261 (2004).

${ }^{16}$ I. Ursu and E. Burzo, J. Magn. Res. 8, 274 (1972).

${ }^{17}$ D. Paudyal, Y. Mudryk, Y. B. Lee, V. K. Pecharsky, K. A. Gschneidner, Jr., and B. N. Harmon, Phys. Rev. B 78, 184436 (2008).

${ }^{18}$ D. Paccard, J. Allemand, J. M. Moreau, N. Marcano, and J. C. Gomez Sal, Solid State Sci. 7, 776 (2005).

19 J. A. Blanco, J. I. Espeso, J. Garcia Soldevilla, J. C. Gomez Sal, M. R. Ibarra, C. Marquina, and H. E. Fischer, Phys. Rev. B 59, 512 (1999).

${ }^{20}$ K. Klepp and E. Parthe, Acta Cryst. B36, 774 (1980); K. Klepp and E. Parthe, Acta Cryst. B37, 495 (1981).

${ }^{21}$ D. D. Bacon, M. Hong, E. M. Gyorgy, P. K. Gallagher, S. Nakahara, and L. C. Feldman, Appl. Phys. Lett. 48, 730 (1986). 
${ }^{22}$ Materials Preparation Center, Ames Laboratory of US DOE, Ames, IA, USA, WwW.mpc.ameslab.gov

${ }^{23}$ A. P. Holm, V. K. Pecharsky, K. A. Gschneidner, Jr., R. Rink, and M. N. Jirmanus, Rev. Sci. Instrum. 75, 1081 (2004).

23 H. Okamoto, J. Phase Equilib. 18, 314 (1997).

${ }^{25}$ T. Massalski, Binary alloy phase diagrams (2nd Ed.), Vol. 2, 1990, ASM International.

26 J. Szade, G. Skorek, and A. Winiarski, J. Cryst. Growth 205, 289 (1999).

27 J. S. Meyers, L. S. Chumbley, F. Laabs, and A. O. Pecharsky, Scripta Mater. 47, 509 (2002).

28 O. Ugurlu, L. S. Chumbley, T. A. Lograsso, and D. L. Schlagel, Acta Mater. 53, 3525 (2005).

${ }^{29}$ L. S. Chumbley, O. Ugurlu, R. W. McCallum, K. W. Dennis, Y. Mudryk, K. A.

Gschneidner, Jr., and V. K. Pecharsky, Acta Mater. 56, 527 (2008).

${ }^{30}$ V. I. Anisimov, F. Aryasetiawan, and A.I. Lichtenstein, J. Phys.: Condens. Matter. 9, 767 (1997).

31 O. K. Andersen and O. Jepsen, Phys. Rev. Lett. 53, 2571 (1984).

32 P. Blaha, K. Schwarz, G. Madsen, D. Kvasnicka, and J. Luitz, WIEN2k, An Augmented Plane Wave + Local Orbitals Program for Calculating Crystal Properties (Karlheinz Schwarz, Techn. Universität Wien, Austria), ISBN 3-9501031-1-2 (2001). 
Table 1. WDS data for the matrix phases in selected annealed $\mathrm{GdNi}_{1-\mathrm{x}} \mathrm{Co}_{\mathrm{x}}$ samples. Note a negligible difference between $\mathrm{x}(\mathrm{Co})_{\text {nom. }}$ and $\mathrm{x}(\mathrm{Co})_{\text {meas. }}$ Tolerances are one standard deviation of the data set.

\begin{tabular}{|c|c|c|c|c|c|c|c|c|c|c|c|c|}
\hline \multirow{3}{*}{$\begin{array}{l}\mathrm{x}(\mathrm{Co}) \text { (nom.) } \\
0.00\end{array}$} & \multicolumn{9}{|c|}{ Average measured atomic ratio (O-corrected) } & \multirow{2}{*}{\multicolumn{3}{|c|}{$\mathrm{x}(\mathrm{Co})$ (meas.) }} \\
\hline & \multicolumn{3}{|c|}{$\mathrm{Ni}$} & \multicolumn{3}{|c|}{$\mathrm{Co}$} & \multicolumn{3}{|c|}{ Gd } & & & \\
\hline & 49.62 & \pm & 0.26 & 0.00 & \pm & 0.00 & 50.38 & \pm & 0.26 & 0.00 & \pm & 0.00 \\
\hline 0.15 & 42.49 & \pm & 0.40 & 7.22 & \pm & 0.44 & 50.29 & \pm & 0.47 & 0.15 & \pm & 0.01 \\
\hline 0.30 & 35.25 & \pm & 0.84 & 14.73 & \pm & 0.83 & 50.02 & \pm & 0.22 & 0.29 & \pm & 0.02 \\
\hline
\end{tabular}




\section{Figure captions}

Fig. 1. a) Rietveld refinement of the X-ray powder diffraction pattern of the as cast GdNi alloy; b) Rietveld refinement of the X-ray powder diffraction pattern of the $\mathrm{GdNi}_{0.7} \mathrm{Co}_{0.3}$ alloy annealed at $700{ }^{\circ} \mathrm{C}$ for 18 days; c) X-ray powder diffraction patterns of as cast $\mathrm{GdNi}_{1-\mathrm{x}} \mathrm{Co}_{\mathrm{x}}$ alloys measured at room temperature.

Fig. 2. SEM image of $\mathrm{GdNi}_{0.7} \mathrm{Co}_{0.3}$ alloy annealed at $800^{\circ} \mathrm{C}$ for 1 week obtained in backscattered electron (composition) mode showing composition contrast. Light (matrix) has composition of $\mathrm{GdNi}_{0.7} \mathrm{Co}_{0.3}$, dark (spots) have composition of $\mathrm{Gd}(\mathrm{Ni}, \mathrm{Co})_{2}$.

Fig. 3. a) Lattice expansion of the $\mathrm{GdNi}_{1-\mathrm{x}} \mathrm{Co}_{\mathrm{x}}$ alloys as a function of Co content at ambient conditions; b) Magnetostriction of binary GdNi compound measured at $60 \mathrm{~K}$ using the X-ray temperature- and magnetic-field-dependent powder diffraction experiments.

Figure 4. (a) Magnetization of the heat-treated $\mathrm{GdNi}_{1-\mathrm{x}} \mathrm{Co}_{\mathrm{x}}$ alloys $(x=0,0.1,0.2,0.3)$ measured as a function of temperature in $1 \mathrm{kOe} d \mathrm{c}$ magnetic field. The $\mathrm{M}(\mathrm{T})$ curves for other compositions are omitted for clarity; (b) The composition dependence of the $\mathrm{T}_{\mathrm{C}}$ of the main phase with transition temperatures determined from the $\mathrm{d} M / \mathrm{d} T$ plots.

Fig 5. TEM bright field image of $\mathrm{GdNi}_{0.7} \mathrm{Co}_{0.3}$ (as-cast) alloy showing bend contours (marked by white arrows) across multiple linear features (marked by black arrows) 
suggesting a single grain or common orientation among matrix regions between the linear features.

Fig. 6. (a) Magnetization and reciprocal mass susceptibility of heat-treated $\mathrm{GdNi}_{0.85} \mathrm{Co}_{0.15}$ alloy measured in $30 \mathrm{kOe}$ dc field; (b) Magnetization of heat-treated $\mathrm{GdNi}_{0.85} \mathrm{Co}_{0.15}$ alloy as a function of applied magnetic field measured at $\mathrm{T}=2 \mathrm{~K}$.

Fig. 7. Lattice parameters of the $\mathrm{GdNi}_{0.85} \mathrm{Co}_{0.15}$ (annealed at $800{ }^{\circ} \mathrm{C}$ for 7 days) determined from $\mathrm{x}$-ray powder diffraction data collected as a function of temperature in 0 and 40 kOe magnetic fields.

Fig. 8. Density of states (DOS) of hypothetical "GdCo" and real GdNi compounds near the Fermi level. Upper row: DOS of "GdCo" (a) and GdNi (b) calculated using the experimentally determined CrB-type crystal structure and lattice constants of $\mathrm{GdNi}$ at 20 K. Lower row: DOS of "GdCo" (c) and GdNi (d) calculated using CrB-type crystal structure and lattice constants of $\mathrm{GdNi}_{0.7} \mathrm{Co}_{0.3}$ at room temperature. 

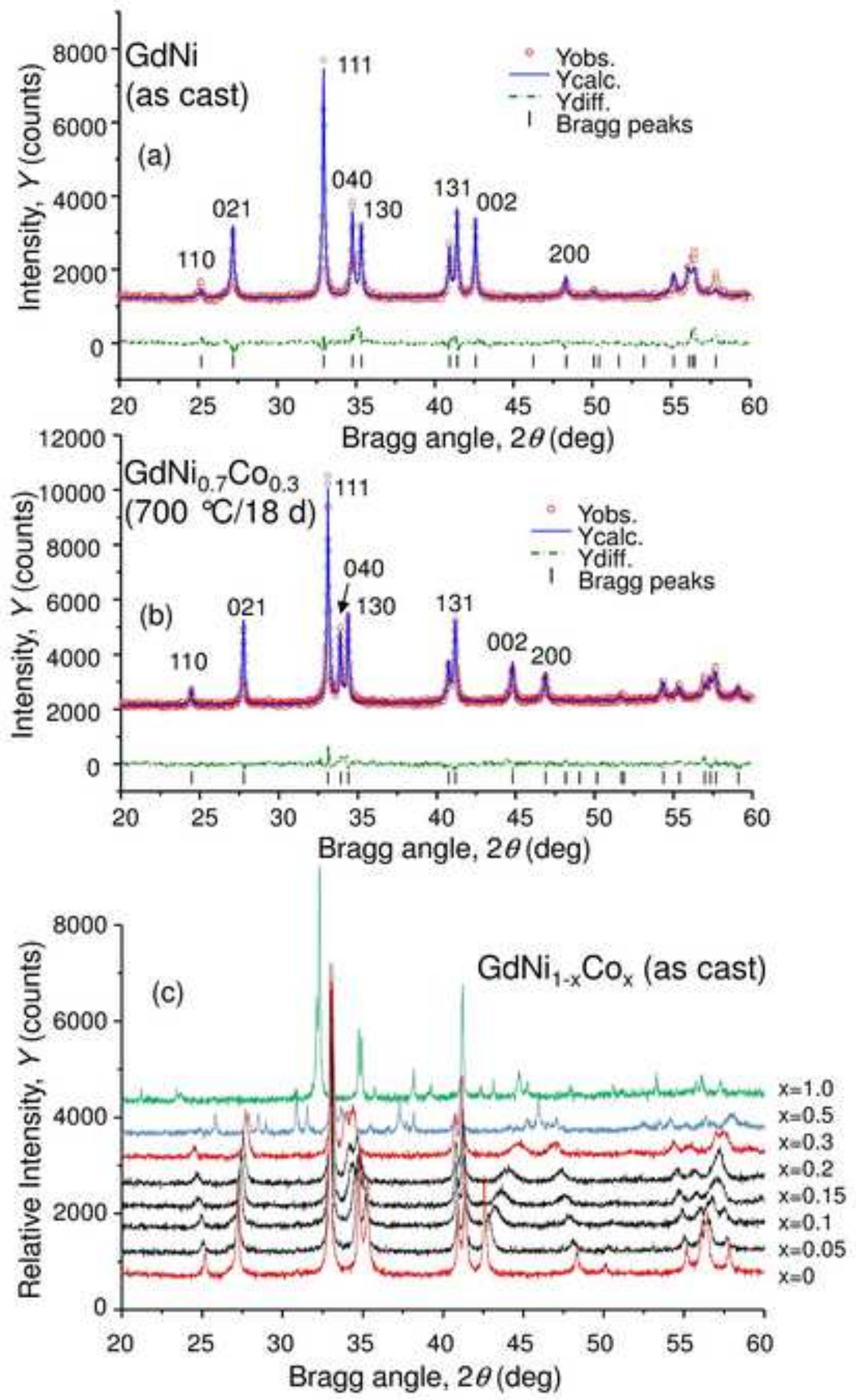


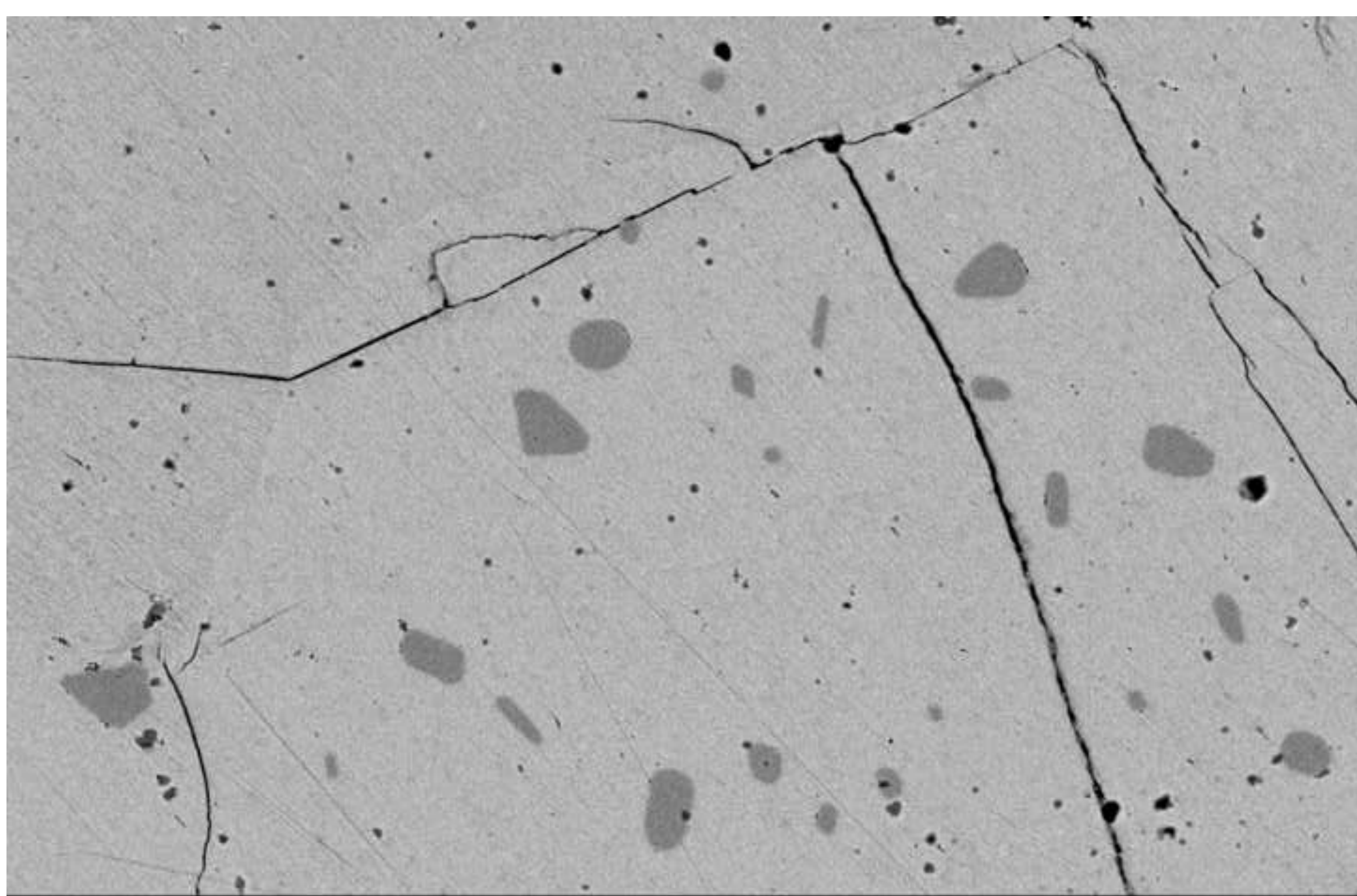

$29 k U$

G $59 \mu \mathrm{m}$ GEG1 1139 BEC 

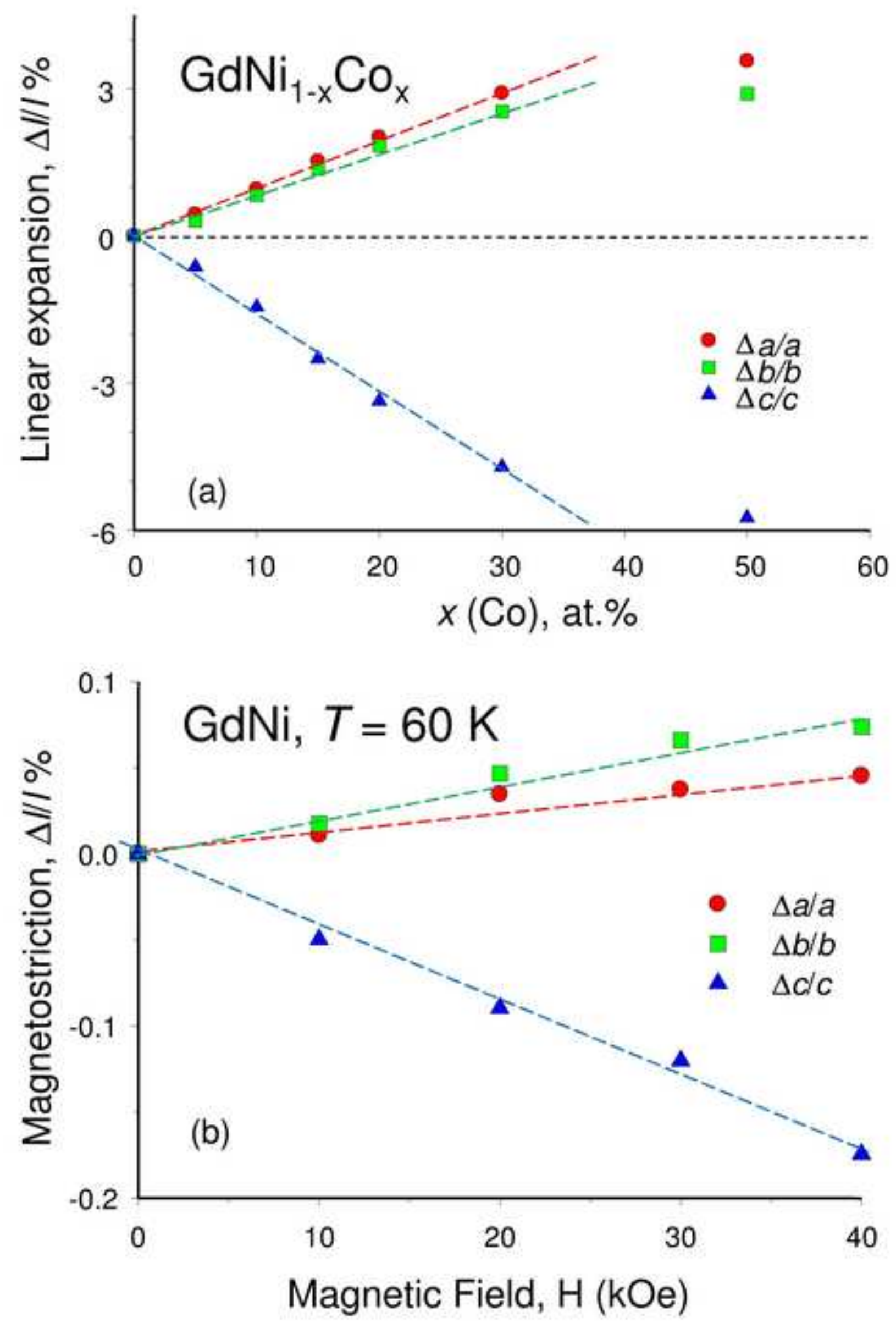

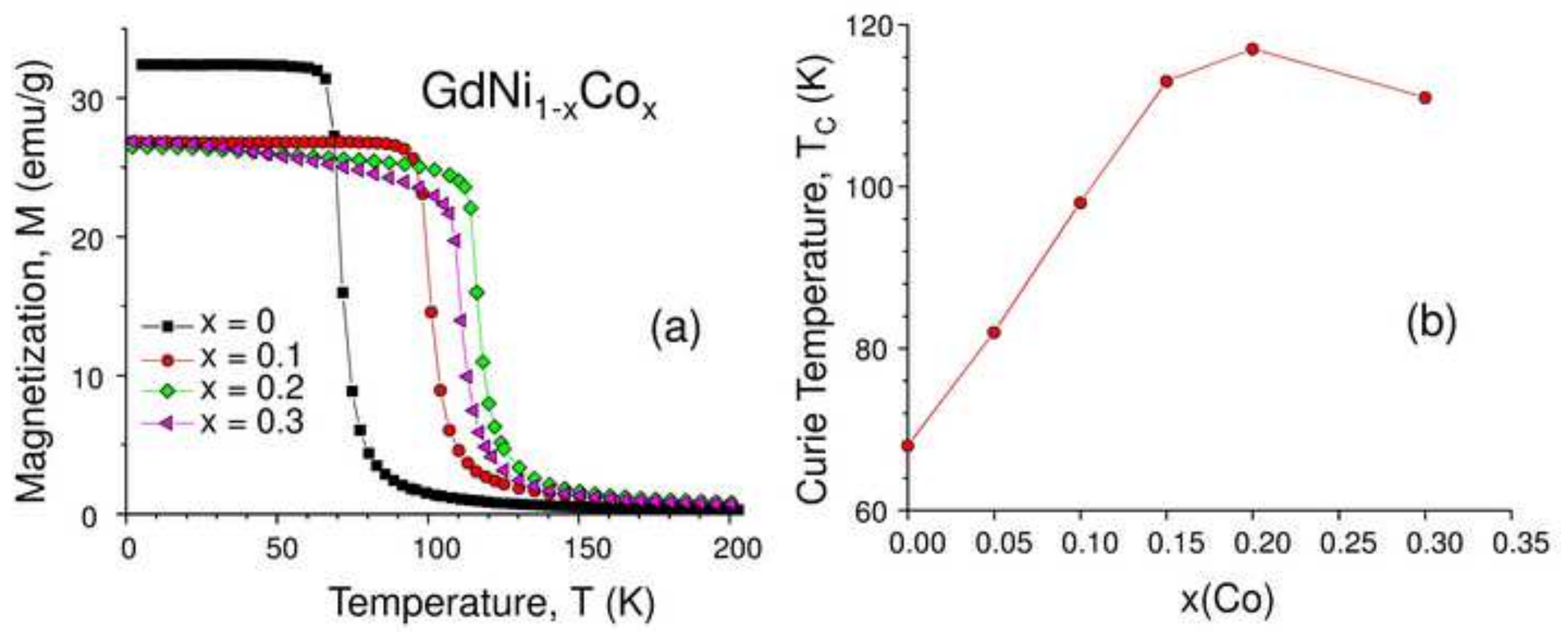


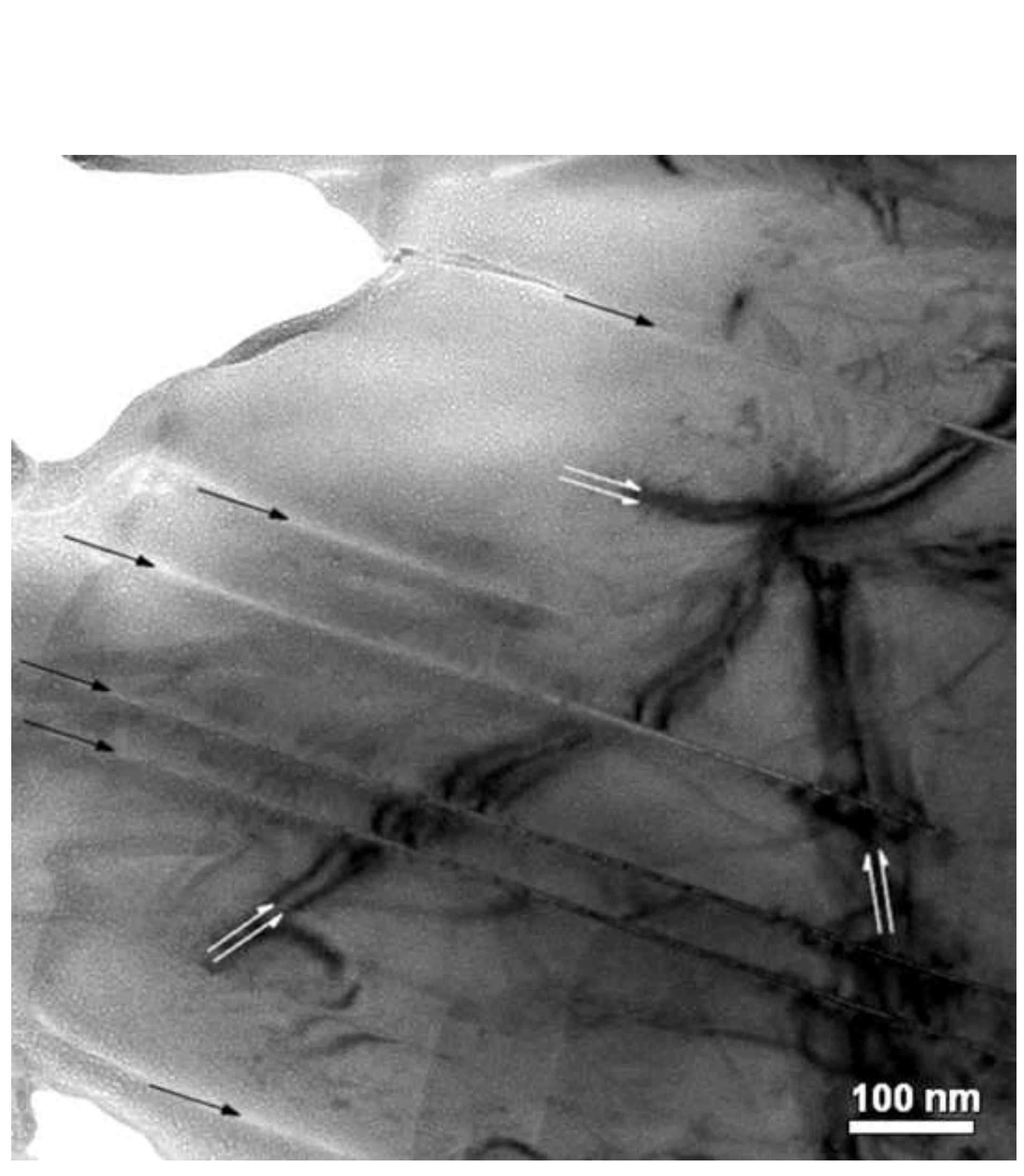

Figure 5

$100 \mathrm{~nm}$

5



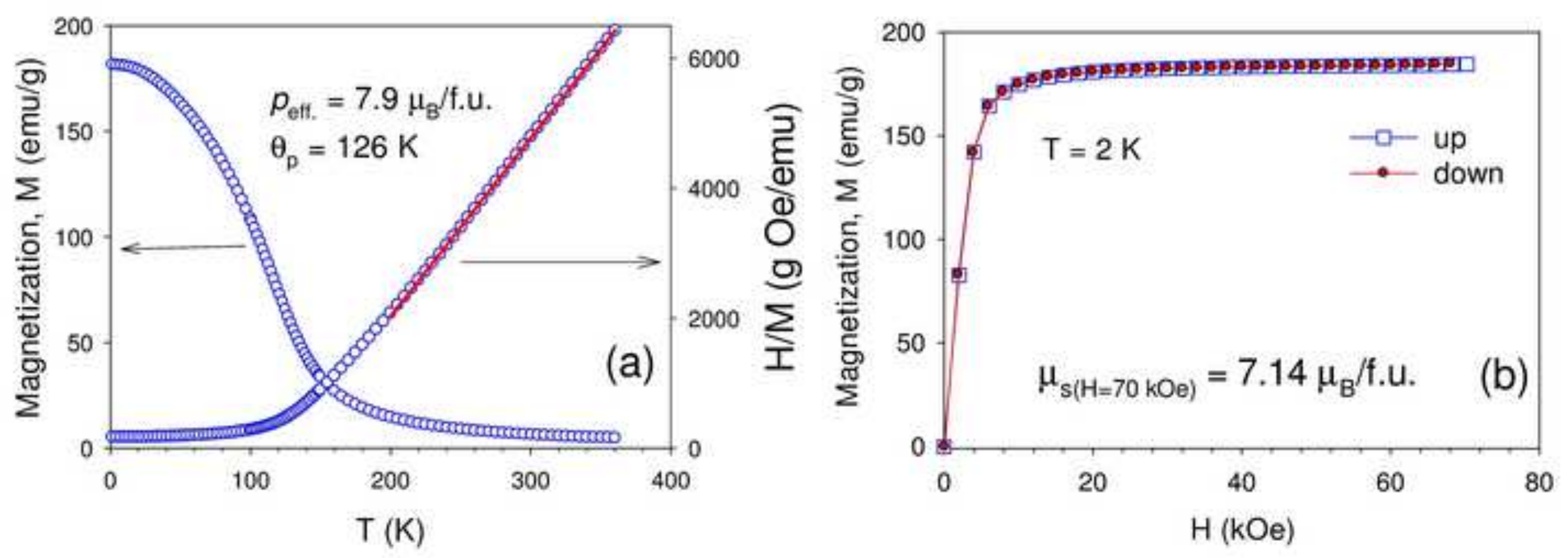


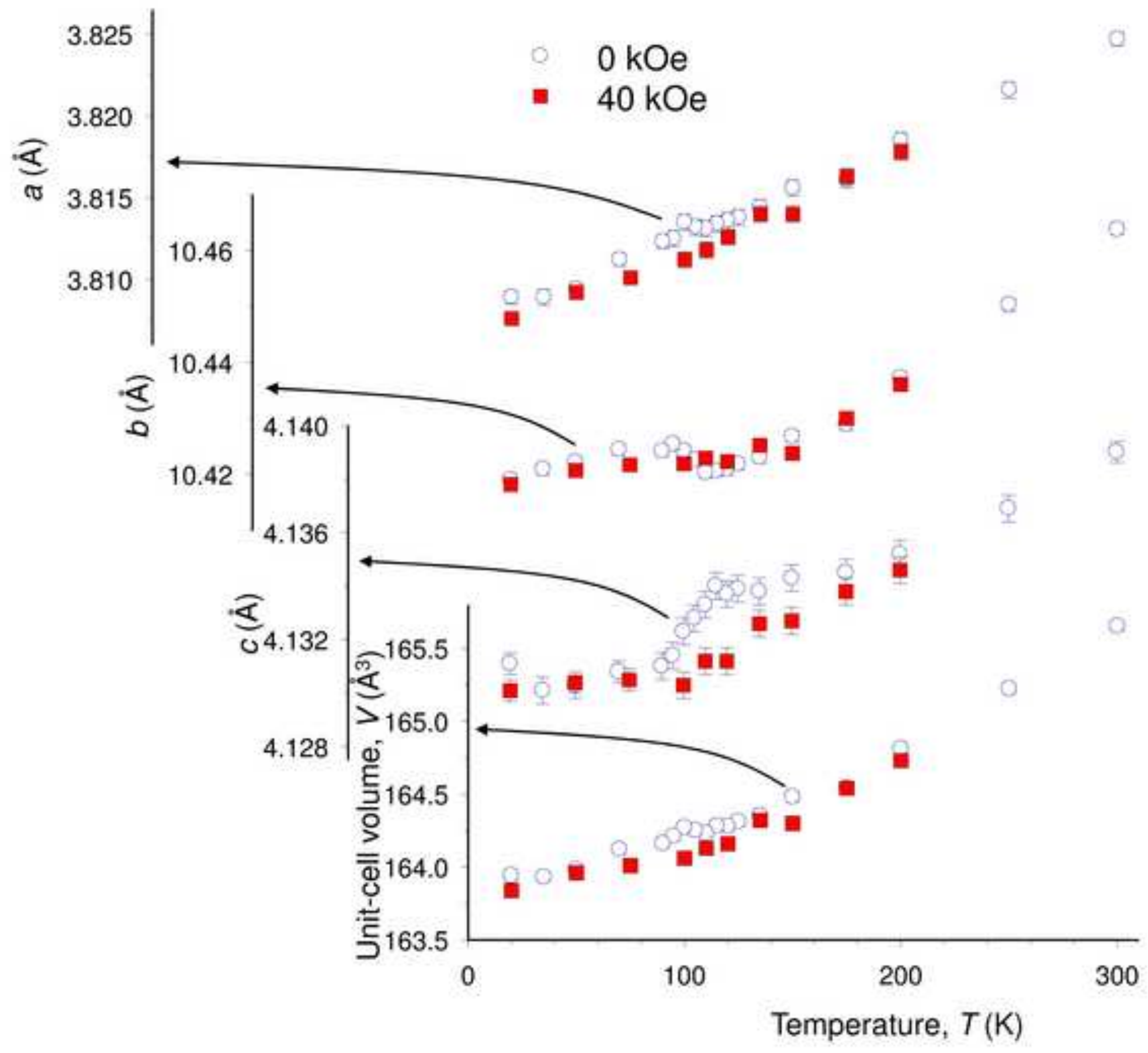


(a) "GdCo"

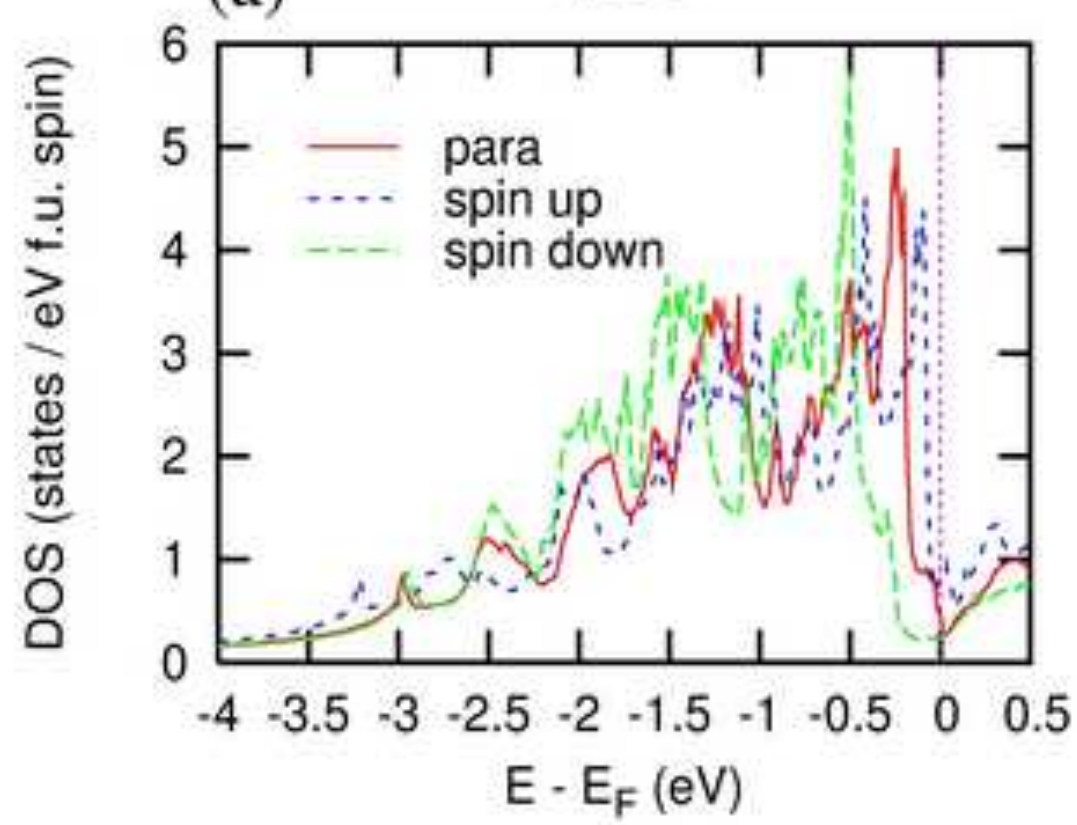

(c)

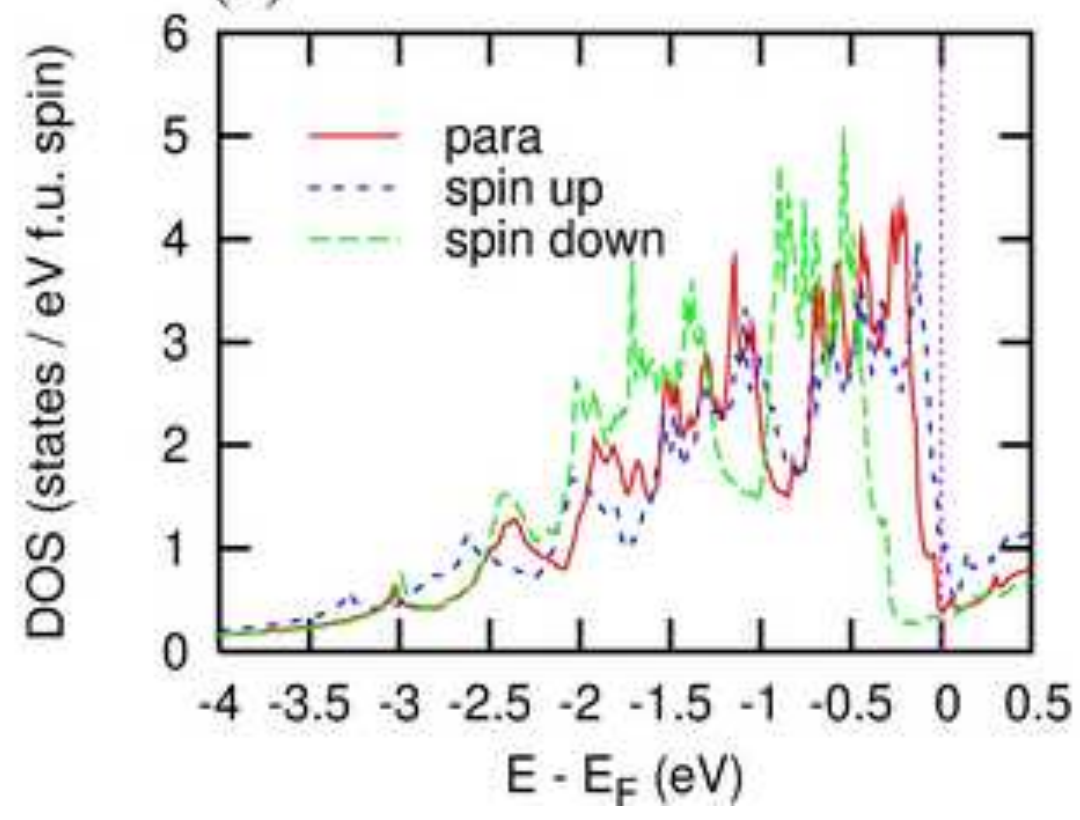

(b)

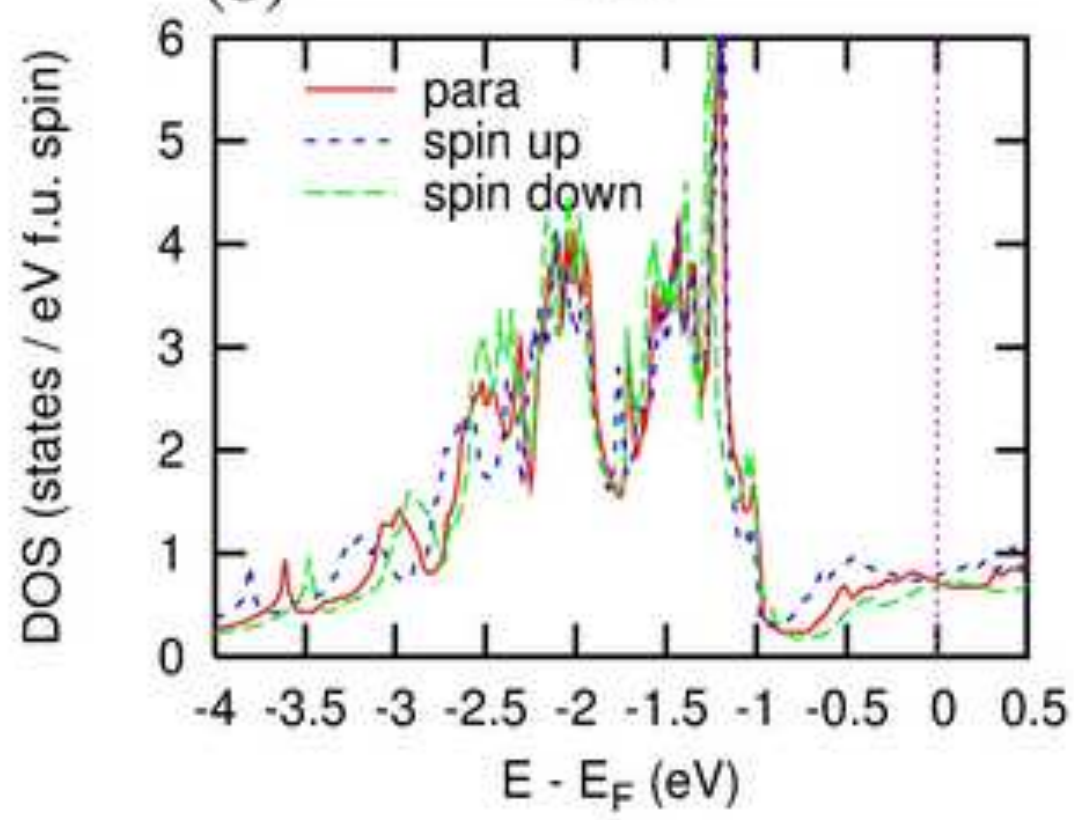

(d)

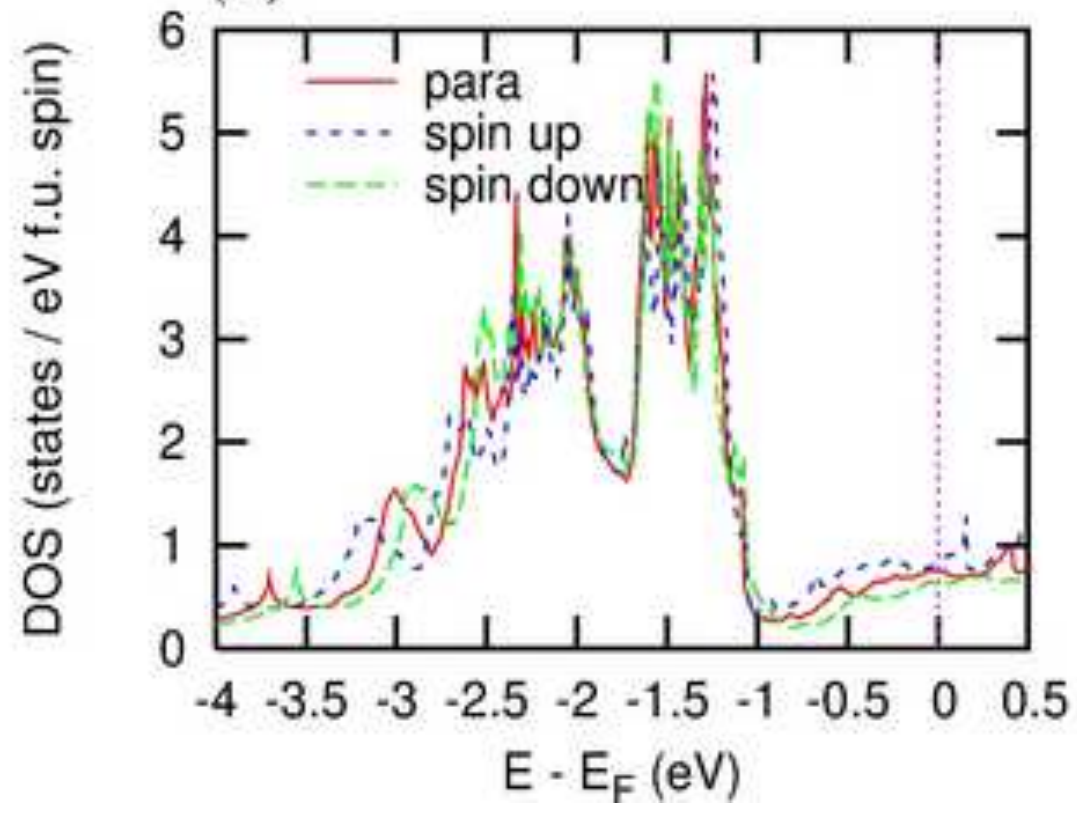



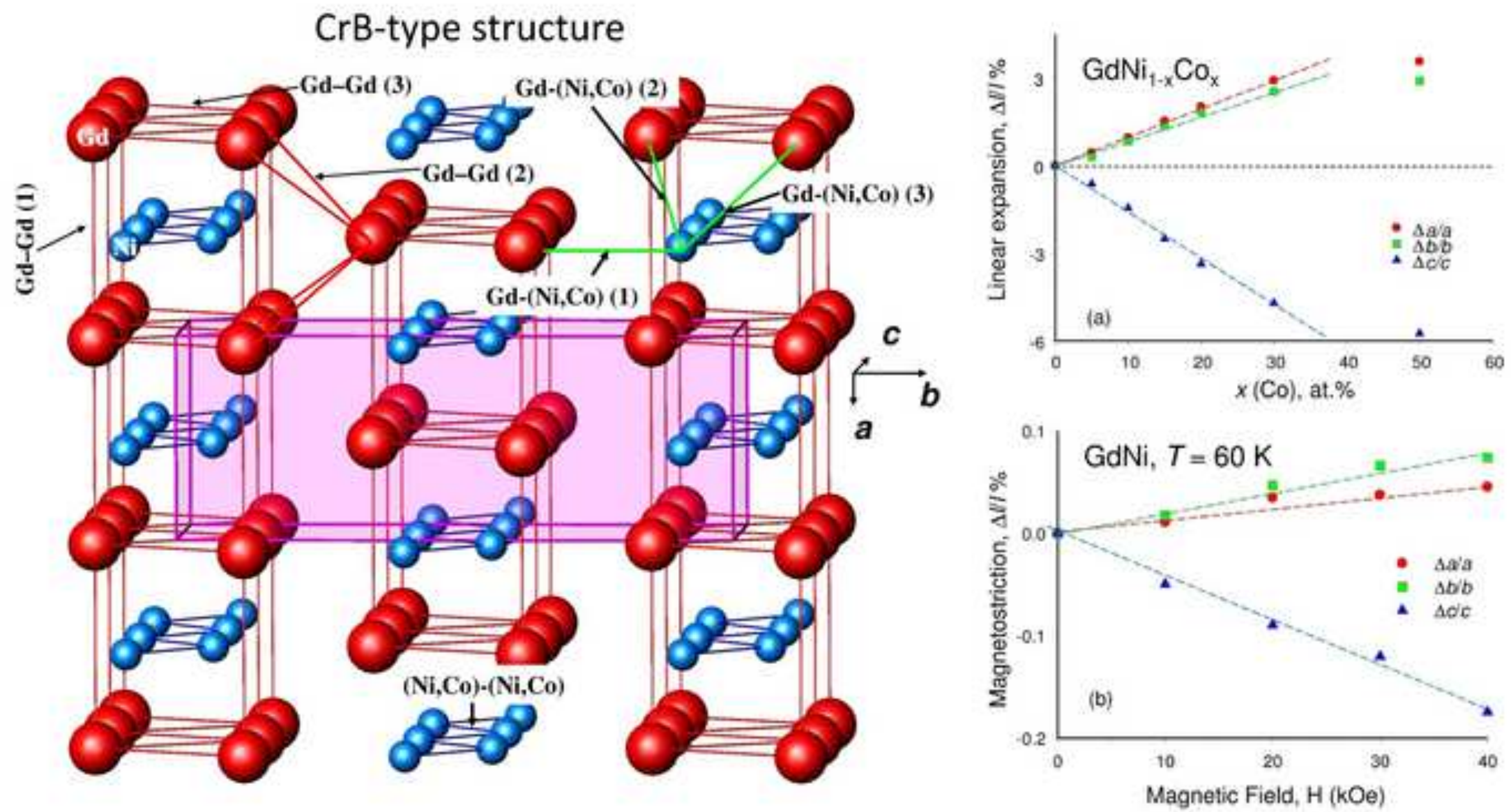